\title{
Dust Impact Monitor (SESAME-DIM) measurements at comet 67P/Churyumov-Gerasimenko
}

\author{
Harald Krüger $^{1}$, Klaus J. Seidensticker ${ }^{2}$, Hans-Herbert Fischer ${ }^{3}$, Thomas Albin ${ }^{1,4}$, Istvan Apathy ${ }^{5}$, Walter Arnold ${ }^{6,7}$, \\ Alberto Flandes ${ }^{8,1}$, Attila Hirn ${ }^{5,1}$, Masanori Kobayashi ${ }^{9}$, Alexander Loose ${ }^{1}$, Attila Péter ${ }^{5}$, and Morris Podolak ${ }^{10}$ \\ ${ }^{1}$ Max-Planck-Institut für Sonnensystemforschung, Justus-von-Liebig-Weg 3, 37077 Göttingen, Germany \\ e-mail: krueger@mps.mpg.de \\ 2 Deutsches Zentrum für Luft- und Raumfahrt, Institut für Planetenforschung, Rutherfordstraße 2, 12489 Berlin, Germany \\ 3 Deutsches Zentrum für Luft- und Raumfahrt, MUSC, Linder Höhe, 51147 Köln, Germany \\ 4 Medical Radiation Physics, Faculty VI, Carl von Ossietzky University, Oldenburg, Germany \\ 5 MTA Centre for Energy Research, Hungarian Academy of Sciences, 1121 Budapest, Hungary \\ ${ }^{6}$ Department of Material Science and Material Technology, Saarland University, 66123 Saarbrücken, Germany \\ 7 1. Physikalisches Institut, Universität Göttingen, Friedrich-Hund-Platz 1, 37077 Göttingen, Germany \\ 8 Ciencias Espaciales, Instituto de Geofísica, Universidad Nacional Autónoma de México, Coyoacán 04510 D.F., Mexico \\ 9 Planetary Exploration Research Center, Chiba Institute of Technology, Narashino, 275-0016 Chiba, Japan \\ 10 Department of Geosciences, Tel Aviv University, 69978 Tel Aviv, Israel
}

Received 24 April 2015 / Accepted 15 September 2015

\begin{abstract}
Context. The Rosetta lander Philae successfully landed on the nucleus of comet 67P/Churyumov-Gerasimenko on 12 November 2014. Philae carries the Dust Impact Monitor (DIM) on board, which is part of the Surface Electric Sounding and Acoustic Monitoring Experiment (SESAME). DIM employs piezoelectric PZT sensors to detect impacts by submillimeter- and millimeter-sized ice and dust particles that are emitted from the nucleus and transported into the cometary coma.

Aims. The DIM sensor measures dynamical data such as flux and the directionality of the impacting particles. Mass and speed of the particles can be constrained assuming density and elastic particle properties.

Methods. DIM was operated during three mission phases of Philae at the comet: (1) before the separation of Philae from Rosetta at distances of about $9.6 \mathrm{~km}, 11.8 \mathrm{~km}$, and $25.3 \mathrm{~km}$ from the nucleus barycenter. In this mission phase particles released from the nucleus on radial trajectories remained undetectable because of significant obscuration by the structures of Rosetta, and no dust particles were indeed detected; (2) during Philae's descent to its nominal landing site Agilkia, DIM detected one approximately millimeter-sized particle at a distance of $5.0 \mathrm{~km}$ from the nucleus' barycenter, corresponding to an altitude of $2.4 \mathrm{~km}$ from the surface. This is the closest ever dust detection at a cometary nucleus by a dedicated in situ dust detector; and (3) at Philae's final landing site, Abydos, DIM detected no dust impact which may be due to low cometary activity in the vicinity of Philae or due to shading by obstacles close to Philae, or both.

Results. Laboratory calibration experiments showed that the material properties of the detected particle are compatible with a porous particle having a bulk density of approximately $250 \mathrm{~kg} \mathrm{~m}^{-3}$. The particle could have been lifted off the comet's surface by sublimating water ice.
\end{abstract}

Key words. comets: individual: 67P/Churyumov-Gerasimenko - space vehicles: instruments - meteorites, meteors, meteoroids

\section{Introduction}

On 6 August 2014 the European spacecraft Rosetta (Glassmeier et al. 2007) encountered its target comet 67P/ChuryumovGerasimenko (hereafter 67P) and became the first artificial satellite of a cometary nucleus. Rosetta carried the lander spacecraft Philae on board (Bibring et al. 2007), which on 12 November 2014 successfully landed on the surface of 67P at a heliocentric distance of $2.99 \mathrm{AU}$ (Biele et al. 2015). One of the scientific instruments on board Philae is the Dust Impact Monitor (DIM) which is part of the Surface Electric Sounding and Acoustic Monitoring Experiment (SESAME; Seidensticker et al. 2007).

Comet 67P is a short-period comet with a present orbital period of about 6.6 years and aphelion and perihelion distances at 5.68 $\mathrm{AU}$ and 1.24 $\mathrm{AU}$, respectively. What we know about 67P before the arrival of Rosetta was summarized by Lamy et al. (2007). Nucleus images recently taken by the cameras on board Rosetta show an irregularly shaped body with a size of about $4 \mathrm{~km}$ that consists of two lobes connected by a short depression, and a wide diversity in surface morphology (Thomas et al. 2015).

In situ investigations of comets 1P/Halley, 81P/Wild 2, and 9P/Tempel 1 showed that micrometer-sized particles dominate the dust population in their comae within several hundred kilometers of their nuclei (McDonnell et al. 1991; Tuzzolino et al. 2004; Economou et al. 2013). The existence of larger millimeter- to centimeter-sized particles in cometary comae is also shown by meteor streams that can be attributed to individual comets (Jenniskens 2006). Particles up to tens of centimeters 
A\&A 583, A15 (2015)

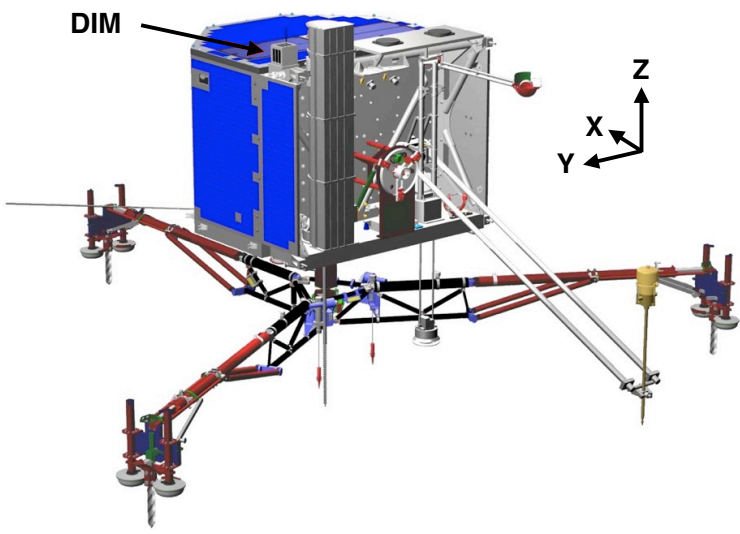

Fig. 1. Rosetta lander Philae. The DIM sensor is visible at the top. Drawing ESA/ATG medialab.

were reported from the flyby of the Deep Impact spacecraft at comet 103P/Hartley 2 (A'Hearn et al. 2011).

Earth-based observations performed before Rosetta's arrival indicate that particles in the size range from $10 \mu \mathrm{m}$ to $1 \mathrm{~mm}$, or possibly even larger, may exist in the coma of 67P (Tozzi et al. 2011). Millimeter-sized particles also exist in the dust trail (Agarwal et al. 2007), and recent investigations with Rosetta revealed millimeter- to centimeter-sized particles in the close vicinity of the nucleus of 67P (Rotundi et al. 2015). Although a significant fraction of these large particles move more slowly than the escape speed near the cometary nucleus, escaping particles in this size range may contribute considerably to the nucleus' total mass loss.

The DIM sensor is mounted on the top side of Philae (Fig. 1) and measures submillimeter- and millimeter-sized particles hitting piezoelectric sensor plates. It measures dynamical data such as flux and the directionality of the impacting particles. The mass and speed of the particles can be constrained assuming particle density and elastic properties (Seidensticker et al. 2007).

DIM was operated for a total of $280 \mathrm{~min}$ before the separation of Philae from Rosetta; for a total of $35 \mathrm{~min}$ after the separation when Philae was descending to its nominal landing site on the surface of 67P, named Agilkia; and for $280 \mathrm{~min}$ at the final landing site, named Abydos. The goal of the DIM measurements at $67 \mathrm{P}$ was to determine the abundance and the particle size distribution in the submillimeter to millimeter size range in order to constrain the mass loss from the comet in the form of large dust particles. Measurements of the temporal variability in the dust flux were foreseen and were aimed at diurnal and seasonal variations in dust release from the cometary surface close to Philae's landing site. Furthermore, the material properties of the detected particles were to be constrained with DIM.

In Sect. 2 we give a brief overview of Philae's mission to comet 67P. Section 3 describes the DIM instrument and its operation on board Philae, and in Sect. 4 we present the DIM dust measurements at comet 67P. In Sect. 5 we analyze the data and in Sect. 6 we discuss our results. Finally, in Sect. 7 we summarize our conclusions.

\section{Philae mission}

The Rosetta spacecraft was launched on 2 March 2004. After swing-bys at Earth and Mars, and flybys at the asteroids S̆teins and Lutetia, Rosetta arrived at its target comet 67P in mid 2014. The spacecraft was brought into an orbit about the comet's nucleus on 6 August 2014, with an initial altitude of $100 \mathrm{~km}$. Until mid October 2014 the orbit was reduced stepwise to $10 \mathrm{~km}$.

Rosetta carried the lander spacecraft Philae on board which attempted the first ever landing on a cometary nucleus. Philae was separated from Rosetta on 12 November 2014 at 08:35:00 UTC. At that time Rosetta was at a distance of $22.7 \mathrm{~km}$ from the comet's barycenter, corresponding to an altitude of about $20.5 \mathrm{~km}$ from the surface (Biele et al. 2015). During the descent, Philae was rotating about its $+Z$ axis. After a seven-hour descent, Philae reached the comet surface and made its first touchdown at 15:34:04 UTC at the Agilkia landing site. The touchdown speed relative to the comet surface was $1.0 \mathrm{~m} \mathrm{~s}^{-1}$.

Owing to failures of its anchoring mechanism and active descent system, Philae did not come to rest at Agilkia. Instead, the spacecraft bounced and continued its journey across the surface of 67P. It came to rest about two hours later at 17:31:17 UTC (Biele et al. 2015). The final landing site, Abydos, is approximately $1.2 \mathrm{~km}$ from Agilkia and, to date, Philae's location is only known with an uncertainty of approximately $21 \times 34 \mathrm{~m}^{2}$ (Kofman et al. 2015).

At Abydos, Philae encountered very low ambient temperatures varying from $90 \mathrm{~K}$ to $130 \mathrm{~K}$ between night and day (Spohn et al. 2015). The insolation of Philae's solar arrays lasted only for about $1.5 \mathrm{~h}$ per comet day (comet rotation period $12.4043 \pm 0.0007 \mathrm{~h}$ after its 2009 perihelion; Mottola et al. 2014). The low temperatures, the short solar insolation period, as well as images of Philae's environment taken by the cameras on board (Bibring et al. 2015) that show cliffs and walls a few meters away indicate that Philae came to rest in some type of cavity. Philae may be tilted by approximately $90^{\circ}$ with its instrument balcony (-X side) pointing to the ground (Bibring et al. 2015, cf. Fig. 1).

Philae was successfully operated from battery power during its nominal mission at Abydos which lasted for about $56 \mathrm{~h}$. All instruments on board were operated during this period, including DIM. When the batteries were exhausted, Philae went into hibernation because the insolation of the solar arrays was too low for the continuing operation of the spacecraft. During the following months, the comet was approaching the Sun and passed through its perihelion on 13 August 2015, leading to a gradual increase in the insolation. On 13 June 2015 contact with Philae was established again, opening the possibility for extended measurements at the comet surface that were never foreseen for Philae, i.e., during the highest activity phase of 67P.

\section{Dust Impact Monitor}

The piezoelectric sensors of DIM are mounted on a cube of about $7 \mathrm{~cm}$ side length. Three sides of the cube are covered with sensors, the other three sides are either closed by aluminum plates or left open for harness access. The DIM cube is mounted on the top side of Philae, and the three active sensor sides point in the $+\mathrm{X},+\mathrm{Y}$, and $+\mathrm{Z}$ directions in the Philae coordinate system (Fig. 2). Each of the active DIM sides is divided into three equally sized segments that carry rectangular piezoelectric sensors made of PNZT7700 (Pb, Ni, Zi, Ti; hereafter PZT). The size of each segment is $50 \times 16 \times 1 \mathrm{~mm}^{3}$. Adding all nine active segments gives a total sensor area of about $70 \mathrm{~cm}^{2}$. More details of the DIM sensor can be found in Seidensticker et al. (2007) and Flandes et al. (2013, 2014).

Each particle impact onto one of the piezoelectric sensor plates generates an electric pulse that is registered with the instrument electronics. The output signal can be approximated by 


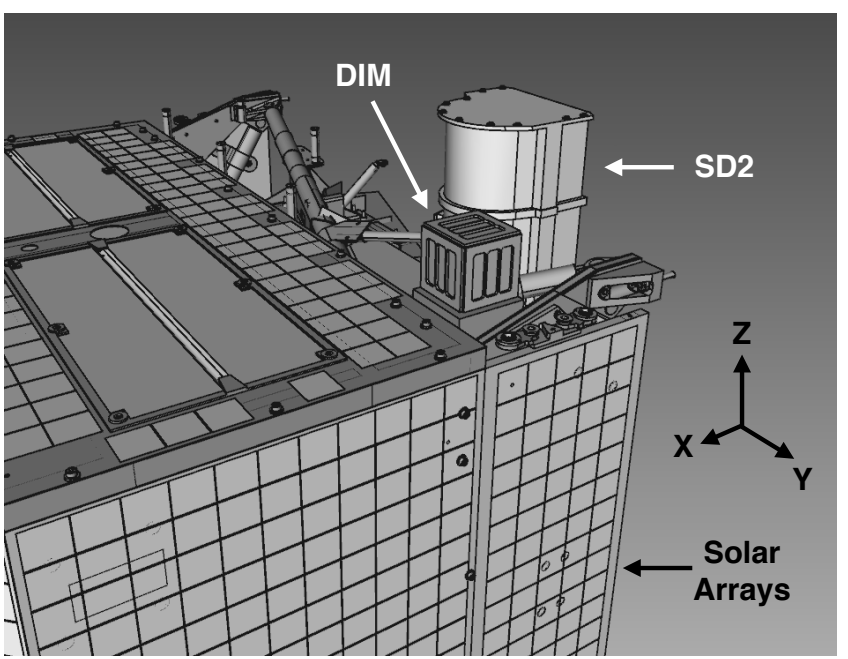

Fig. 2. Detail of Philae. The DIM cube with its three active sensor sides is visible at the top. The housing of the SD2 drill is also indicated.

a damped sine wave, and the measured signals are analyzed by the Hertzian theory of contact mechanics (Hertz 1882; Johnson 1985). The amplitude and the width of the first half-sine pulse are used to derive particle properties such as the reduced modulus and the mass. To calibrate the instrument signals, we performed a large number of drop experiments with particles made of different materials, including water ice as a cometary analogue material (Flandes et al. 2013, 2014).

\subsection{DIM impact measuring values}

Two parameters, impact duration $T_{\mathrm{c}}$ and peak voltage $U_{\mathrm{m}}$, are derived from the signal curve by the instrument electronics. These values are transmitted to Earth (Flandes et al. 2013).

To distinguish noise or false events from real dust impacts, we use the term "impact" for true dust impacts only, and we use the term "noise", "false event", or "long event" for all other registered events (cf. Sect. 3.3 for a definition of these event types). The simple term "event" is used in a general sense, referring to both real dust impacts and all other types of registered events. In addition, we use the term "false signal" for events that are characterized by the instrument software as true dust impacts but for which we know by other means that they cannot be due to dust impacts. The instrument software is not able to distinguish between false signals and dust impacts. We use the term "dust" as a synonym for both ice or dust particles.

\subsubsection{Impact duration}

The impact duration is derived from the number of counts of a $20 \mathrm{MHz}$ clock. The conversion between impact duration on a logarithmic scale to microseconds is given by Eq. (A.1) in Appendix A.

The false and long events are identified by using algorithms specified by Péter \& Lucás (2001), see also Sect. 3.3. These events are defined according to the measured impact duration. They are counted with an onboard counter and only their total numbers are transmitted to Earth. The impact durations are transmitted for true dust impacts, but not for false or long events.

\subsubsection{Peak voltage}

The instrument provides the peak voltage of a single dust impact after logarithmic amplification. The amplifier transfer function of the DIM flight model is given by Eq. (A.2) in Appendix A, and a fixed logarithmic scaling is used for storage as given by Eq. (A.3).

The transfer characteristics of the logarithmic DIM amplifier can vary with time. It was regularly checked by a calibration procedure (cf. Sect. 3.2).

\subsubsection{Event time}

In addition to the impact duration and the peak voltage of a signal, the time in UTC when the event occurred is also stored for up to 350 events transmitted in Burst Continuous Test 2 mode (not in Burst Continuous mode; see Sect. 3.2 for a description of these measurement modes).

\subsection{DIM operational modes}

DIM can be operated by telecommands from the Earth. Before any DIM measurement is started, a few operations have to be performed to guarantee that DIM is working properly. We can only give an overview here; more details about the DIM operation can be found in Fischer (2012).

After DIM is switched on (A) a power check is performed to verify that the supply voltages are within predefined limits, then (B) electronic noise is measured on the DIM amplifier (with the DIM sensor disconnected). Starting from a very low value, the detection threshold (the margin; see Sect. 3.4) is increased by steps of $10 \mathrm{~dB}$ until no further false event is detected. The rates of false events typically encountered in flight were such that the margin was set to $30 \mathrm{~dB}$ or $40 \mathrm{~dB}$ (cf. Tables 1 and 2). This means that a true dust impact must have an amplitude of at least approximately $0.1 \mathrm{mV}$ or $0.25 \mathrm{mV}$, respectively, to overcome the threshold of the amplifier (Krüger et al. 2012). In the next step (C), a DIM sensor test checks whether all three sensor sides are operational. An electrical pulse (approximately $5 \mathrm{~V}$ for $10 \mu \mathrm{s}$ ) is applied to each sensor side and the response is registered in the same way a dust impact would be measured. Finally (D), the electronics performs a DIM calibration - two test pulses are applied to the logarithmic amplifier - to re-calibrate the transfer characteristic of the logarithmic amplifier and to check the time measuring $\left(T_{\mathrm{c}}\right)$ circuit. Pulse height and duration are $1 \mathrm{mV}$ and $8 \mu \mathrm{s}$ for low level, and $100 \mathrm{mV}$ and $20 \mu \mathrm{s}$ for high level, respectively.

The results of the calibration procedure were supposed to be used to re-calibrate the amplifier transfer function in the data evaluation on Earth. However, it was discovered after launch that the high-level value is in saturation for temperatures below $+20{ }^{\circ} \mathrm{C}$ so that this re-calibration procedure could not be applied. We therefore used the amplifier transfer function measured before launch throughout the data evaluation presented in this paper, which is given by Eq. (A.2). The uncertainty caused by this deficiency is taken into account in our error estimation (cf. Sect. 3.6).

After successful execution of the steps listed above, DIM was ready to measure dust impacts. Two measurement modes were used to measure dust at the comet. Single events on one sensor side can be registered in the so-called Burst Continuous (BC) Mode. The measured peak amplitude $U_{\mathrm{m}}$ and the impact duration $T_{\mathrm{c}}$ are stored in a compressed way: they are scaled to a logarithmic scale $\boldsymbol{U}_{\mathrm{m}}$ and $\boldsymbol{T}_{\mathrm{c}}$ according to Eqs. (A.1) and (A.3), and the counts for impacts or false signals with a particular $\left[\boldsymbol{U}_{\mathrm{m}}, \boldsymbol{T}_{\mathrm{c}}\right]$ combination are stored in memory cells of different sizes depending on the expected frequency of such events 
Table 1. DIM measurement details at comet 67P when Philae was connected to Rosetta.

\begin{tabular}{|c|c|c|c|c|}
\hline $\begin{array}{l}\text { Meas. } \\
\text { number } \\
\text { (1) } \\
\end{array}$ & Day & $\begin{array}{c}\text { Start } \\
\text { time } \\
\text { [UTC] } \\
(3)\end{array}$ & $\begin{array}{c}\text { Distance } \\
{[\mathrm{km}]} \\
(4)\end{array}$ & $\begin{array}{c}\text { Margin } \\
\text { [dB] } \\
(5) \\
\end{array}$ \\
\hline 1 & 16.10 .2014 & $20: 12: 03$ & 11.8 & 30 \\
\hline 2 & 16.10 .2014 & $20: 22: 23$ & 11.8 & 40 \\
\hline 3 & 16.10 .2014 & $20: 36: 04$ & 11.8 & 30 \\
\hline 4 & 16.10 .2014 & $20: 46: 24$ & 11.8 & 40 \\
\hline 5 & 17.10 .2014 & $08: 42: 04$ & 11.0 & 30 \\
\hline 6 & 17.10 .2014 & $08: 52: 24$ & 11.0 & 40 \\
\hline 7 & 17.10 .2014 & 09:06:04 & 10.9 & 30 \\
\hline 8 & 17.10 .2014 & $09: 16: 25$ & 10.9 & 40 \\
\hline 9 & 17.10.2014 & $10: 32: 06$ & 10.7 & 30 \\
\hline 10 & 17.10 .2014 & $10: 42: 26$ & 10.7 & 40 \\
\hline 11 & 17.10 .2014 & $10: 56: 06$ & 10.7 & 30 \\
\hline 12 & 17.10 .2014 & 11:06:26 & 10.6 & 40 \\
\hline 13 & 17.10 .2014 & $12: 42: 06$ & 10.4 & 30 \\
\hline 14 & 17.10 .2014 & $12: 52: 26$ & 10.4 & 40 \\
\hline 15 & 17.10 .2014 & 13:06:06 & 10.3 & 30 \\
\hline 16 & 17.10 .2014 & $13: 16: 26$ & 10.3 & 40 \\
\hline 17 & 17.10 .2014 & $13: 52: 06$ & 10.2 & 30 \\
\hline 18 & 17.10 .2014 & $14: 02: 26$ & 10.2 & 40 \\
\hline 19 & 17.10 .2014 & $14: 16: 06$ & 10.2 & 30 \\
\hline 20 & 17.10 .2014 & $14: 26: 26$ & 10.1 & 40 \\
\hline 21 & 17.10 .2014 & $15: 02: 04$ & 10.0 & 30 \\
\hline 22 & 17.10 .2014 & $15: 12: 25$ & 10.0 & 40 \\
\hline 23 & 17.10 .2014 & $15: 26: 04$ & 10.0 & 30 \\
\hline 24 & 17.10.2014 & $15: 36: 25$ & 9.9 & 40 \\
\hline 25 & 17.10 .2014 & $17: 22: 06$ & 9.6 & 30 \\
\hline 26 & 17.10 .2014 & $17: 32: 26$ & 9.6 & 40 \\
\hline 27 & 17.10 .2014 & $17: 46: 06$ & 9.6 & 30 \\
\hline 28 & 17.10 .2014 & $17: 56: 26$ & 9.6 & 40 \\
\hline
\end{tabular}

Notes. Column 1 lists the measurement number, Cols. 2 and 3 give the start time of each measurement block (all times are given in lander onboard time), Col. 4 lists the distance from the comet barycenter, and Col. 5 gives the margin. All measurements were collected with the $\mathrm{X}$ sensor side in BCT2 mode with a measurement duration of $600 \mathrm{~s}$. DIM was partially obscured by Rosetta during these measurements, see text for details.

(regular characters $U_{\mathrm{m}}$ and $T_{\mathrm{c}}$ denote the raw uncompressed data; bold characters $\boldsymbol{U}_{\mathrm{m}}$ and $\boldsymbol{T}_{\mathrm{c}}$ denote the compressed logarithmic values). Each BC measurement starts with a $10 \mathrm{~s}$ instrument warm-up period, which is not included in the measuring time.

In addition to the BC mode (which delivers the $\left[\boldsymbol{U}_{\mathrm{m}}, \boldsymbol{T}_{\mathrm{c}}\right]$ matrix), the instrument can be operated in a so-called Burst Continuous Test 2 mode (BCT2). Similar to the BC mode, the BCT2 mode delivers $U_{\mathrm{m}}$ and $T_{\mathrm{c}}$ for each individual impact. Here the raw uncompressed data are transmitted instead of the compressed logarithmic values, as well as the event time when the impact or false signal was registered. The number of data sets for impacts that can be stored and transmitted to Earth in BCT2 mode is limited to 350 .

\subsection{Measurement of single impacts}

A DIM measurement consists of a series of single-event measurements. Each of these measurements detects and evaluates one event by comparing the amplified sensor signal $U_{\text {out }}$ with the detection threshold voltage $U_{\text {thr }}$ (cf. Sect. 3.4). The underlying assumption is that the initial part of the dust impact signal can be approximated by the first half of a sine wave. An impact should thus show up as a voltage that crosses the threshold voltage upwards, followed by a second crossing of the threshold voltage downwards. The period between the two threshold crossings defines the impact duration $T_{\mathrm{c}}$.

If the amplified sensor signal crosses the detection threshold too early (less than $1 \mathrm{~ms}$ after the single-event measurement was initialized), the event is classified as a false event, otherwise it is accepted as the beginning of a potential real impact. The measurement is stopped after $0.5 \mathrm{~ms}$. The event is ruled out as a long event, if no second threshold crossing is detected during the measurement duration. A true dust impact is thus characterized by its occurrence later than $1 \mathrm{~ms}$ after the initialization of the measurement and by a duration of less than $0.5 \mathrm{~ms}$.

Regardless of the event type (dust impact, false, or long event), an adjustable dead time, the so-called sensor signal decay time (Flandes et al. 2013), is included after the end of each single event measurement. It was set to $5 \mathrm{~ms}$ for all measurements. Apart from the signal decay time, several waiting and latency periods are added to the total duration of a single impact measurement. All latency periods add up to a total instrument dead time of approximately $10 \mathrm{~ms}$ (Fischer 2014).

\subsection{Margin}

The DIM electronics can detect an event if the amplified signal voltage exceeds an adaptive threshold value $U_{\mathrm{thr}}$. The detection threshold $U_{\text {thr }}$ is the sum of an adjustable margin and a signal average. The margin can be increased in steps of $10 \mathrm{~dB}$ in the range 10-70 $\mathrm{dB}$. Each step changes the threshold voltage by approximately $0.3 \mathrm{~V}$. The signal average is determined by the DIM electronics with a time constant of approximately $1 \mathrm{~s}$. It varies slowly with impact properties and frequency, aiming at covering a wide range of event voltage levels. Measuring values for the respective sensor side of the signal average are transmitted to Earth if sampling of average values is commanded.

\subsection{Electronics ageing}

The performance of the DIM instrument electronics has been regularly checked since Rosetta's launch in 2004. So-called payload checkouts of the instruments on board were performed approximately every six months between 2004 and 2011, and again in 2014. No such procedures were executed between 2011 and early 2014 when Rosetta was in hibernation.

During these checkouts the DIM operational procedures described in Sect. 3.2 were executed. They did not reveal any ageing of the instrument electronics, except a deficiency in the calibration procedure (D) described in Sect. 3.2. We therefore conclude that the performance of the DIM electronics remained stable during the entire Rosetta mission.

\subsection{Temperature dependence}

Operational periods when the DIM electronics noise was measured and sensor tests were performed during flight showed no significant temperature dependence (operational procedures $\mathrm{B}$ and $\mathrm{C}$ in Sect. 3.2). On the other hand, a strong correlation between calibration measurements (operational procedure $\mathrm{D}$ in Sect. 3.2) and the estimated DIM electronics temperatures could be observed: between $-40{ }^{\circ} \mathrm{C}$ and $+30{ }^{\circ} \mathrm{C}$ the impact durations for the high calibration peaks decreased by $8 \%$, and those of the low calibration peak by $20 \%$. The low calibration peak 
H. Krüger et al.: Dust Impact Monitor (SESAME-DIM)

Table 2. DIM measurement details on 12 November 2014 when Philae was still connected to Rosetta and during the descent to the comet's surface.

\begin{tabular}{|c|c|c|c|c|c|c|c|c|c|}
\hline $\begin{array}{l}\text { Meas. } \\
\text { numb. } \\
\text { (1) }\end{array}$ & $\begin{array}{l}\text { Day } \\
\text { (2) }\end{array}$ & $\begin{array}{c}\text { Start } \\
\text { time } \\
{[\mathrm{UTC}]} \\
(3)\end{array}$ & $\begin{array}{c}\text { Dist. } \\
{[\mathrm{km}]} \\
(4)\end{array}$ & $\begin{array}{c}\text { Meas. } \\
\text { time } \\
{[\mathrm{s}]} \\
(5)\end{array}$ & $\begin{array}{c}\text { DIM } \\
\text { side } \\
(6)\end{array}$ & $\begin{array}{l}\text { Margin } \\
\\
{[\mathrm{dB}]} \\
(7)\end{array}$ & $\begin{array}{c}\text { Signal-free } \\
\text { period } \\
{[\%]} \\
(8)\end{array}$ & $\begin{array}{c}\text { False signal } \\
\text { frequency } \\
{\left[\mathrm{s}^{-1}\right]} \\
(9)\end{array}$ & $\begin{array}{l}\text { Comments } \\
\text { (10) }\end{array}$ \\
\hline 29 & 12.11 .2014 & 07:38:02 & 25.3 & 100 & $\mathrm{X}$ & 40 & 100 & - & DIM partially obscured by Rosetta \\
\hline- & 12.11.2014 & 08:35:00 & 22.4 & - & - & - & - & - & Philae release from Rosetta \\
\hline $\begin{array}{l}30 \\
31 \\
32\end{array}$ & $\begin{array}{l}12.11 .2014 \\
12.11 .2014 \\
12.11 .2014\end{array}$ & $\begin{array}{l}08: 38: 32 \\
08: 42: 23 \\
08: 46: 13\end{array}$ & $\begin{array}{l}22.2 \\
22.1 \\
22.0\end{array}$ & $\begin{array}{l}200 \\
200 \\
200\end{array}$ & $\begin{array}{l}X \\
Y \\
Z\end{array}$ & $\begin{array}{l}40 \\
40 \\
40\end{array}$ & $\begin{array}{c}0 \\
0 \\
99\end{array}$ & $\begin{array}{l}- \\
83 \\
68\end{array}$ & Meas. terminated at $08: 38: 45 \mathrm{UTC}$ \\
\hline $\begin{array}{l}33 \\
34 \\
35\end{array}$ & $\begin{array}{l}12.11 .2014 \\
12.11 .2014 \\
12.11 .2014\end{array}$ & $\begin{array}{c}08: 50: 03 \\
08: 53: 52 \\
08: 57: 42\end{array}$ & $\begin{array}{l}21.8 \\
21.6 \\
21.4\end{array}$ & $\begin{array}{l}200 \\
200 \\
200\end{array}$ & $\begin{array}{l}\mathrm{X} \\
\mathrm{Y} \\
\mathrm{Z}\end{array}$ & $\begin{array}{l}50 \\
50 \\
50\end{array}$ & $\begin{array}{l}100 \\
100 \\
100\end{array}$ & $\begin{array}{l}- \\
- \\
-\end{array}$ & \\
\hline $\begin{array}{l}36 \\
37 \\
38\end{array}$ & $\begin{array}{l}12.11 .2014 \\
12.11 .2014 \\
12.11 .2014\end{array}$ & $\begin{array}{l}09: 59: 04 \\
10: 02: 54 \\
10: 06: 44\end{array}$ & $\begin{array}{l}18.6 \\
18.4 \\
18.3\end{array}$ & $\begin{array}{l}200 \\
200 \\
200\end{array}$ & $\begin{array}{l}X \\
Y \\
Z\end{array}$ & $\begin{array}{l}40 \\
40 \\
40\end{array}$ & $\begin{array}{c}0 \\
99 \\
0\end{array}$ & $\begin{array}{l}112 \\
32 \\
77\end{array}$ & \\
\hline $\begin{array}{l}39 \\
40 \\
41\end{array}$ & $\begin{array}{l}12.11 .2014 \\
12.11 .2014 \\
12.11 .2014\end{array}$ & $\begin{array}{l}14: 40: 04 \\
14: 42: 14 \\
14: 44: 24\end{array}$ & $\begin{array}{l}5.1 \\
5.0 \\
4.9\end{array}$ & $\begin{array}{l}100 \\
100 \\
100\end{array}$ & $\begin{array}{l}X \\
Y \\
Z\end{array}$ & $\begin{array}{l}40 \\
40 \\
40\end{array}$ & $\begin{array}{c}96 \\
98 \\
0\end{array}$ & $\begin{array}{l}93 \\
47 \\
77\end{array}$ & Noise terminated at $14: 42: 26$ UTC \\
\hline- & 12.11.2014 & $15: 34: 04$ & 2.3 & - & - & - & - & - & Philae touchdown at Agilkia \\
\hline
\end{tabular}

Notes. Column 1 lists the measurement number, Cols. 2 and 3 give the start time of each measurement block, Col. 4 gives the distance from the barycenter of the comet's nucleus, Col. 5 lists the measurement time, Col. 6 gives the sensor side operated, Col. 7 lists the margin, Col. 8 lists the fraction of the signal-free time in the measurement period, Col. 9 lists the frequency of false signals, and Col. 10 gives some comments. All measurements were collected in BCT2 mode.

amplitudes varied within $\pm 4 \%$ and showed a non-monotonous dependence as a function of the electronics temperature. High calibration peak amplitudes were not included in the analysis since the values were saturated in a wide temperature range. The temperature dependence of the system, to a large extent, can be attributed to the temperature dependence of the logarithmic amplifier.

\section{Dust measurements at comet 67P}

Before the launch of Rosetta, DIM was designed to measure dust particles after Philae had landed on the surface of the cometary nucleus. Measurements before the separation from Rosetta and during Philae's descent were not foreseen, and were added later on in the planning process of the mission.

\subsection{DIM operation}

After Rosetta arrived at comet 67P on 6 August 2014 and before Philae was released on 12 November 2014, DIM was operated three times, namely on 16 and 17 October 2014 and on 12 November 2014 (Tables 1 and 2, measurements 1 to 29). When Philae was connected to Rosetta, the DIM sensor was strongly shielded by the Rosetta structures. Only the $\mathrm{DIM}+\mathrm{X}$ sensor side was operated in these time intervals because it was the least obscured side (Sect. 4.3). DIM was operated in BCT 2 mode for a total of 280 minutes. No dust impact and only very few false signals were registered.

When Philae was descending to its first touchdown point Agilkia on 12 November 2014, DIM was operated in BCT2 mode for a total of $35 \mathrm{~min}$. Measurements were taken sequentially with all three sensor sides (Table 2, measurements 30 to 41). The descent trajectory of Philae close to the nucleus and the altitudes of the DIM measurement periods are shown in Figs. 3 and 4.

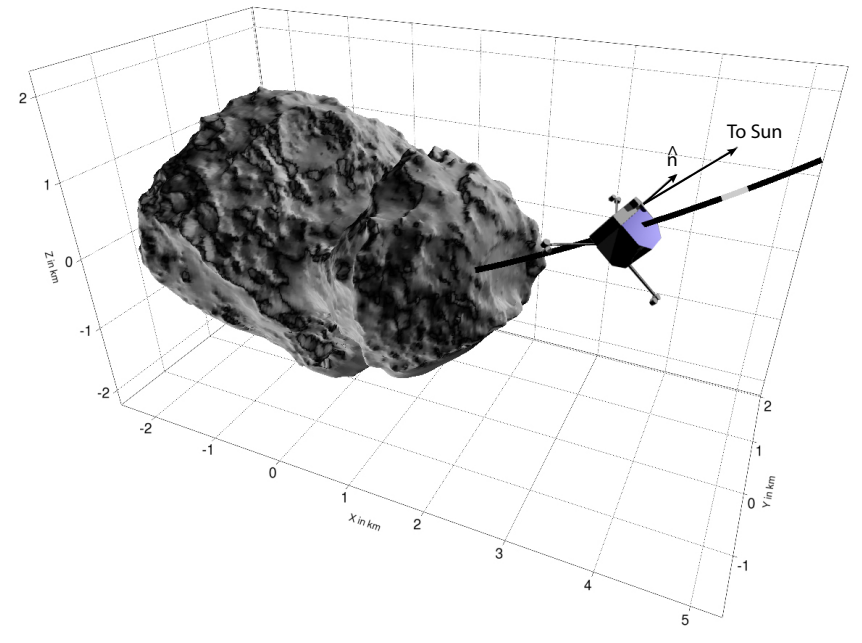

Fig. 3. Philae trajectory close to the surface of comet $67 \mathrm{P}$ on 12 November 2014. The trajectory is shown in the comet fixed coordinate system. The position of Philae at the time of the single particle detection is illustrated. The vector $\hat{\boldsymbol{n}}$ represents the normal to the $+\mathrm{Y}$ side of DIM. For the nucleus shape we used the ESA Engineering Model CSHP_DV_096_01_00161.ROS.

Before Philae landed on 67P the entire operational procedures performed on board during the descent were tested with the Philae Ground Reference Model (GRM) at Deutsches Zentrum für Luft- und Raumfahrt (DLR) in Cologne, which is a twin of the Philae spacecraft in space. During these tests a high rate of false signals was registered with the DIM electronics. This noise occurred only when insolation of the solar arrays was simulated, i.e., the signals were due to cross-talk (Hirn et al. 2015). Therefore, we expected a similarly high rate of false signals for the measurements with the DIM flight model during Philae's descent to the nucleus surface on 12 November 2014. 
A\&A 583, A15 (2015)

Table 3. DIM measurement details when Philae was at its final landing site, Abydos.

\begin{tabular}{|c|c|c|c|c|c|c|}
\hline $\begin{array}{l}\text { Meas. } \\
\text { number } \\
\text { (1) }\end{array}$ & Day & $\begin{array}{c}\text { Start } \\
\text { [UTC] } \\
(3)\end{array}$ & $\begin{array}{c}\text { Meas. } \\
\text { time } \\
{[\mathrm{s}]} \\
(4)\end{array}$ & $\begin{array}{l}\text { DIM } \\
\text { side } \\
(5)\end{array}$ & $\begin{array}{l}\text { Margin } \\
\text { [dB] } \\
(6)\end{array}$ & $\begin{array}{c}\text { Illuminated } \\
\text { solar array } \\
\text { (7) }\end{array}$ \\
\hline 42 & 13.11 .2014 & $07: 02: 22$ & 558 & $\mathrm{X}$ & 40 & $\# 2$ \\
\hline 43 & 13.11 .2014 & $07: 12: 10$ & 558 & Y & 40 & None \\
\hline 44 & 13.11 .2014 & $07: 21: 59$ & 558 & Z & 40 & None \\
\hline 45 & 13.11 .2014 & $07: 33: 22$ & 558 & $X$ & 30 & None \\
\hline 46 & 13.11 .2014 & $07: 43: 21$ & 558 & Y & 30 & None \\
\hline 47 & 13.11 .2014 & 07:53:08 & 558 & Z & 40 & None \\
\hline 48 & 13.11 .2014 & 09:04:24 & 558 & $\mathrm{X}$ & 40 & None \\
\hline 49 & 13.11 .2014 & 09:14:13 & 558 & Y & 40 & None \\
\hline 50 & 13.11 .2014 & 09:24:02 & 558 & $\mathrm{Z}$ & 40 & None \\
\hline 51 & 13.11 .2014 & $09: 35: 24$ & 558 & $X$ & 40 & None \\
\hline 52 & 13.11 .2014 & $09: 45: 12$ & 558 & Y & 40 & None \\
\hline 53 & 13.11 .2014 & 09:55:01 & 558 & $\mathrm{Z}$ & 40 & None \\
\hline 54 & 13.11 .2014 & 11:06:24 & 558 & $\mathrm{X}$ & 40 & None \\
\hline 55 & 13.11 .2014 & $11: 16: 13$ & 558 & Y & 40 & None \\
\hline 56 & 13.11 .2014 & $11: 26: 02$ & 558 & $\mathrm{Z}$ & 40 & None \\
\hline 57 & 13.11 .2014 & $11: 37: 24$ & 558 & $\mathrm{X}$ & 40 & None \\
\hline 58 & 13.11 .2014 & $11: 47: 13$ & 558 & Y & 40 & None \\
\hline 59 & 13.11 .2014 & 11:57:02 & 558 & $\mathrm{Z}$ & 40 & None \\
\hline 60 & 13.11 .2014 & $13: 08: 25$ & 558 & $X$ & 40 & None \\
\hline 61 & 13.11 .2014 & $13: 18: 14$ & 558 & Y & 40 & None \\
\hline 62 & 13.11 .2014 & $13: 28: 03$ & 558 & $\mathrm{Z}$ & 40 & None \\
\hline 63 & 13.11 .2014 & $13: 39: 25$ & 558 & $X$ & 40 & None \\
\hline 64 & 13.11 .2014 & $13: 49: 14$ & 558 & Y & 40 & None \\
\hline 65 & 13.11 .2014 & 13:59:03 & 558 & $\mathrm{Z}$ & 40 & None \\
\hline 66 & 14.11 .2014 & $06: 33: 42$ & 557 & $X$ & 30 & $\# 2$ \\
\hline 67 & 14.11 .2014 & $06: 43: 30$ & 557 & $\mathrm{Y}$ & 40 & $\# 2$ \\
\hline 68 & 14.11 .2014 & $06: 53: 18$ & 557 & $\mathrm{Z}$ & 30 & $\# 2$ \\
\hline 69 & 14.11 .2014 & 07:04:41 & 558 & $X$ & 30 & $\# 2,3$ \\
\hline 70 & 14.11 .2014 & $07: 14: 30$ & 558 & $\mathrm{Y}$ & 40 & $\# 2,3$ \\
\hline 71 & 14.11 .2014 & $07: 24: 19$ & 558 & $\mathrm{Z}$ & 40 & $\# 2,3$ \\
\hline
\end{tabular}

Notes. Column 1 lists the measurement number, Cols. 2 and 3 give the start time of each measurement block, Col. 4 gives the measurement duration, Col. 5 the sensor side operated, Col. 6 lists the margin, and Col. 7 gives the solar panel that was most strongly illuminated during the measurement. All measurements were taken in BC mode.

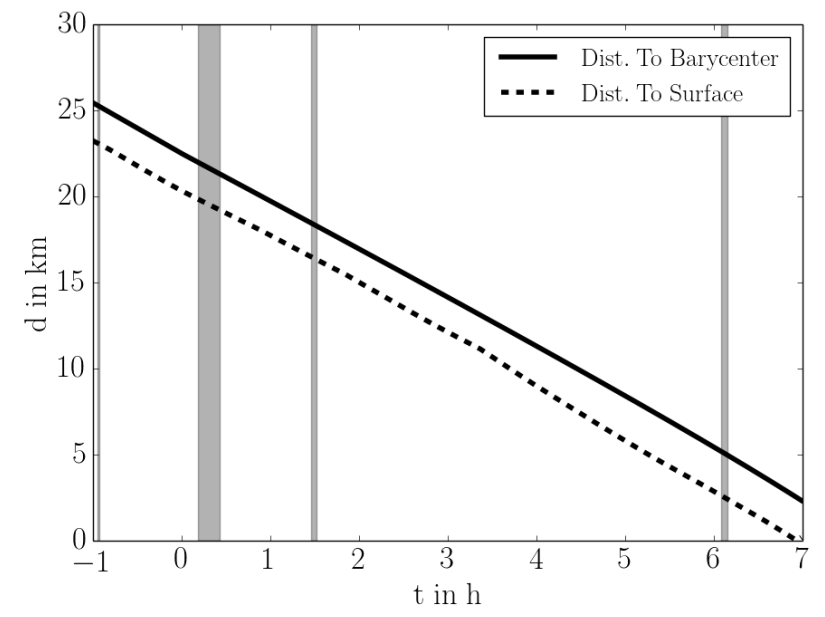

Fig. 4. Altitude of Philae above the nucleus surface and distance from the comet's barycenter, respectively, as a funtion of time during the descent to the nucleus of comet 67P. The time $t=0$ refers to Philae's separation from Rosetta on 12 November 2014; 08:35:00 UTC. Gray vertical bars indicate the operational periods of DIM.

To suppress these signals, we operated the instrument with an increased margin setting for a few of the measurements during the descent: one measurement sequence was performed with margin $40 \mathrm{~dB}$ from 08:38 UTC to 08:46 UTC, while this sequence was repeated with a margin of $50 \mathrm{~dB}$ from 08:50 UTC to 08:57 UTC. A high rate of false signals was indeed registered during a few of the measurement periods with the lower margin setting, while the higher margin effectively prevented the occurrence of false signals. The higher margin setting raised the detection threshold of the instrument to somewhat larger particles (cf. Sect. 5.3) so that only particles with impact signals in excess of about $1 \mathrm{mV}$ could be measured. As occurred during the GRM tests performed earlier, the false signals were likely caused by Philae's solar energy generators (cf. Sect. 4.2).

At the final landing site, Abydos, DIM was operated in BC mode for a total of 280 minutes on 13 and 14 November 2014. Here, all three sensor sides were operated sequentially. Only a few false signals were recorded (Table 3, measurements 42 to 71 ).

\subsection{Dust impact identification}

Reliable identification of false signals in the data set is a prerequisite for the analysis of dust at 67P based on the DIM measurements. In order to characterize the behavior of the instrument 


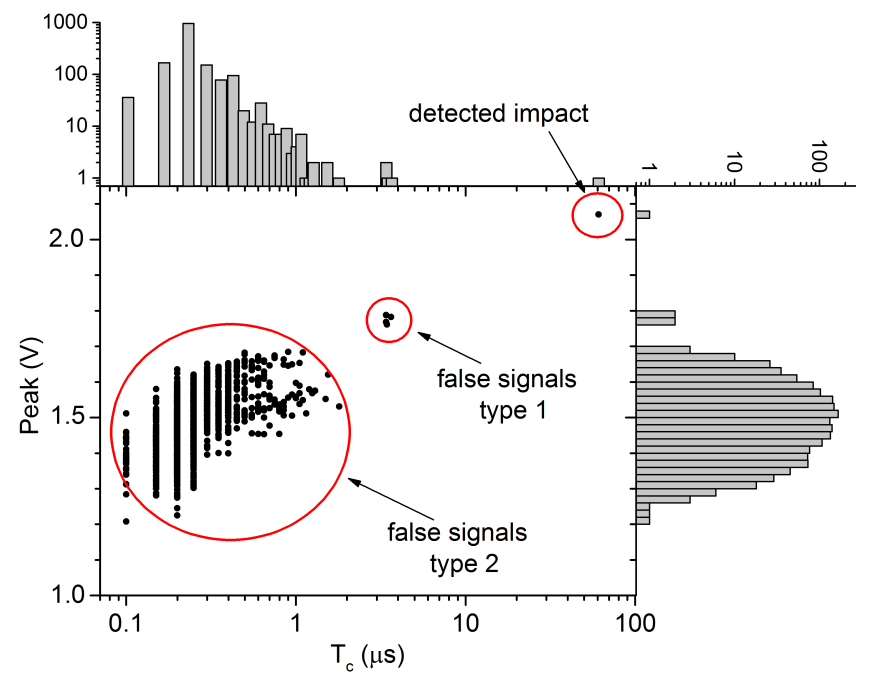

Fig. 5. All detected events (false signals plus dust impacts) in the $\left[U_{\mathrm{m}}, T_{\mathrm{c}}\right]$ diagram. Vertical and horizontal histograms indicate the numbers of detected events.

with respect to false signals, we analyzed DIM data obtained with both the Philae GRM, as well as the data from the DIM Flight Model (FM) on board Philae.

\subsubsection{Signal distribution in the $\left[U_{\mathrm{m}}, T_{\mathrm{c}}\right]$ diagram}

The measured impact durations $T_{\mathrm{c}}$ and signal amplitudes $U_{\mathrm{m}}$ can be used to characterize false events in the DIM data set. The false signals recorded with the GRM instrument during ground tests were found to show a behavior very similar to those measured with the flight instrument on board Philae. Therefore, we concentrate our analysis on the flight data in the following.

We show the distribution of the measured signals in the $\left[U_{\mathrm{m}}, T_{\mathrm{c}}\right]$ diagram in Fig. 5 . The false signals cluster in a very limited region in the $\left[U_{\mathrm{m}}, T_{\mathrm{c}}\right]$ plane. They mostly occur with very short impact durations up to about $1.5 \mu \mathrm{s}$, and amplified signal amplitudes $1300 \mathrm{mV} \lesssim U_{\text {out }} \lesssim 1700 \mathrm{mV}$. A second group of false signals showed impact durations of approximately $3.4 \mu \mathrm{s}$ and signal amplitudes $U_{\text {out }} \approx 1800 \mathrm{mV}$. Clearly separated from this region we detected one single event with a contact duration of $61 \mu \mathrm{s}$, and a signal amplitude of $2070 \mathrm{mV}$.

We never detected false signals with such a large impact duration, neither during the GRM tests nor in earlier FM data. Laboratory experiments performed with ice spheres of about $0.6 \mathrm{~mm}$ radius yielded impact durations below $6 \mu \mathrm{s}$ (Flandes et al. 2014). However, such a large impact duration could be obtained during laboratory experiments with porous particles (see Sect. 5.2). We therefore interpret this event as a true dust impact. It was registered with the DIM $+\mathrm{Y}$ sensor side on 12 November 2014, 14:43:47 UTC during measurement number 40 .

\subsubsection{Temporal behavior of false signals}

During some measurement periods when Philae was descending to the nucleus surface, false signals occurred with a relatively high frequency up to $110 \mathrm{~s}^{-1}$ (Table 2). Very similar signal frequencies were also recorded during tests with the Philae GRM due to cross-talk.

With such high rates of false signals it might be asked whether DIM was able to detect any dust impacts in between the individual false signals. Here, a consideration of the dead time of DIM gives some insights. As described in Sect. 3.3, as a good approximation we consider the dead time to be $10 \mathrm{~ms}$ for both the detected and the false signals. Given that the total event rates during periods with the highest number of false signals are in the range $30 \mathrm{~s}^{-1}$ to $110 \mathrm{~s}^{-1}$, the detection of real impacts during these periods was extremely unlikely. We conclude that DIM was not able to detect any dust particles during these noisy periods. Hence, for estimations of dust fluxes (Hirn et al., in prep.), the use of the length of the quiet period when no false signal was recorded is preferable to the total length of the BCT2 measurement.

It should be noted that the single dust impact recorded on 12 November 2014, 14:43:47 UTC was measured during a BCT2 measurement with 100 s measurement time (Table 2, measurement 40). False signals were recorded only for $2 \mathrm{~s}$ after the start of this measurement, and the dust impact was measured $80 \mathrm{~s}$ later. No false signal was recorded in between. This clearly separates the dust impact from the false signals recorded in this measurement interval.

\subsubsection{False events due to cosmic radiation}

A potential source of false events can be hits by high-energy cosmic ray particles since PZTs show some sensitivity to highenergy radiation. Two major components of cosmic radiation can be distinguished: galactic cosmic rays (GCRs) originating from outside the solar system, and solar cosmic radiation. GCRs consist of energetic charged particles ( $86 \%$ protons, $12 \%$ alpha particles, and heavier ions and electrons typically in the energy range of $1 \mathrm{MeV}$ to $10^{14} \mathrm{MeV}$ ). Solar cosmic radiation is composed of charged particles having a softer (eV to $\mathrm{GeV}$ ) energy spectrum than GCRs. Most of the time the GCR component dominates, although during solar flares the flux of the solar cosmic radiation can be orders of magnitude higher.

High-energy radiation hitting the PZT can generate acoustic signals similar to mechanical impacts that could mimic a dust particle impact. Laboratory experiments with PZT ceramics showed that only bursts of penetrating ions, neutrons, or gamma-photons may cause a signal with a strength of approximately $1 \mathrm{mV}$ (Miyachi et al. 2006, 2010; Adliene et al. 1985; Holbert et al. 2005). No single event was detected either with high-energy ions or high-energy photons, i.e., gamma rays. We can therefore exclude cosmic radiation as a source of false signals in our DIM measurements.

\subsection{Detection geometry}

Before the separation of Philae from Rosetta, the DIM sensor was heavily obscured by the structures of Rosetta and Philae (cf. Fig. 2). While the DIM $+X$ sensor side was only partially obscured by the overhanging structures of Rosetta, the $+Y$ sensor was almost entirely shielded, and the $+Z$ sensor was completely covered. Therefore, only the $+\mathrm{X}$ sensor was operated before Philae's separation.

After the separation from Rosetta the detection geometry was completely different. Figure 2 shows the DIM cube mounted on top of Philae. DIM is partially shielded by the Philae structures and the shielding differs for the three sensor sides. The $+X$ side can only detect dust particles approaching from the $+Z$ direction (top side of Philae), while Philae shields particles approaching from the $-\mathrm{Z}$ hemisphere entirely. The $+\mathrm{Y}$ side is partially shielded for particles approaching from the $-Z$ hemisphere. Finally, the $+Z$ side is partially shielded by the housing 
of Philae's SD2 drill (light gray structure in Fig. 2), but it has the largest field of view of the three sensor sides (Hirn et al., in prep.).

After the separation from Rosetta, Philae was rotating about its $\mathrm{Z}$ axis so that the $+\mathrm{X}$ and the $+\mathrm{Y}$ sides of DIM scanned a complete circle during one Philae revolution, with an offset of $90^{\circ}$ (cf. Fig. 2). Initially after the separation, Philae's rotation period was about $5 \mathrm{~min}$. After the landing gear was unfolded the rotation period increased to about $8.6 \mathrm{~min}$. The landing gear was unfolded at about 08:41 UTC (R. Roll, priv. comm.), i.e., during DIM measurement 30 (Table 2).

\section{Results and analysis}

\subsection{Dust detections}

As described in Sect. 4.1, before and after the separation of Philae from Rosetta, the operational conditions of the DIM instrument differed. We therefore distinguish three measurement intervals and configurations:

(1) Philae connected to Rosetta;

(2) Philae's descent to the comet surface (landing site Agilkia);

(3) Philae at its final landing site Abydos.

\subsubsection{Philae connected to Rosetta}

DIM measurements on 16 and 17 October 2014 were taken at a distance of $9.6 \mathrm{~km}$ and $11.8 \mathrm{~km}$ from the nucleus barycenter, respectively, when Rosetta was orbiting the comet nucleus on an eccentric trajectory. A similar measurement was performed on 12 November 2014, about one hour before Philae's separation from Rosetta, at a distance of $25.3 \mathrm{~km}$ (Meas. numbers 1 to 29; Tables 1 and 2). In all three cases only the $+X$ sensor of DIM was taking measurements because the other sensor sides were strongly obscured (Sect. 4.3).

During these measurements the orientation of Rosetta was such that the DIM $+\mathrm{X}$ sensor was pointing within $\pm 10^{\circ}$ perpendicular to the comet's nadir direction and perpendicular to the direction of motion of Rosetta. With this orientation the DIM $+\mathrm{X}$ sensor could neither detect particles approaching radially from the nucleus nor particles on circular orbits about the nucleus. On the other hand, particles on highly bent ballistic trajectories or particles with highly eccentric orbits could have been detected by the DIM $+X$ side. No dust impact was detected in this configuration during a total of about $280 \mathrm{~min}$ of measurement time.

\subsubsection{Decent of Philae to the comet surface}

Philae was separated from Rosetta on 12 November 2014 at 08:35:00 UTC, and during its seven-hour descent to the surface of the nucleus, all three DIM sensor sides were operated repeatedly with a total measuring time of $35 \mathrm{~min}$ (Table 2 and Fig. 4). During several of these periods the recorded rates of false signals were very high so that no dust impact was detectable between the noise events because of dead time of the instrument electronics (cf. Sect. 4).

Only one single dust impact was detected during the descent to the nucleus surface before the first touchdown at Agilkia. The particle was detected with the DIM +Y side at 14:43:47 UTC at a distance of $5.0 \mathrm{~km}$ from the barycenter of the nucleus, corresponding to an altitude from the nucleus surface of about $2.4 \mathrm{~km}$. At this time Philae was at a latitude of $22^{\circ}$ and a longitude of $346^{\circ}$ in the comet fixed reference frame defined by
Preusker et al. (2015), and the spacecraft's velocity vector was $\left[v_{x}, v_{y}, v_{z}\right]=[-0.817,-0.232,-0.434]\left(\right.$ in $\left.\mathrm{m} \mathrm{s}^{-1}\right)$. The location of the particle detection with respect to the nucleus is shown in Fig. 3.

In order to constrain the particle dynamics from the DIM measurement, the velocity vector (i.e., impact direction and speed) has to be determined. Given that dust particles can hit each DIM sensor side from a wide range of impact angles from almost half a hemisphere, the impact direction is only little constrained (details of the DIM detection geometry will be discussed by Hirn et al., in prep.). In addition, the speed measurement is connected with a large uncertainty (Flandes et al. 2013, 2014). It is therefore impossible to determine the particle dynamics with high accuracy for a single detected particle.

The derivation of the impact direction of the particle is further complicated because Philae was rotating about its $Z$ axis during the descent. Therefore, the $+X$ and $+Y$ sensors of DIM scanned an entire circle during one spin revolution of Philae. No information about the orientation of Philae during the descent was provided by the Philae Science Operations and Navigation Center (SONC) in Toulouse, France, at the time of this writing. Furthermore, attempts to determine the orientation from the magnetic field measurements of the Rosetta Magnetometer and Plasma Monitor (ROMAP) instrument on board Philae (Auster et al. 2015) led to inconclusive results for the interpretation of the DIM data. We attempted to derive the orientation of the DIM sensors as a function of time from the output signals of the solar arrays of Philae (Albin et al., in prep.). This analysis is still ongoing, and we therefore have to postpone a detailed discussion of the DIM detection geometry and the possible particle dynamics to a future publication.

\subsubsection{Final landing site Abydos}

All three sensor sides of DIM were operated at the Abydos landing site for a total of $280 \mathrm{~min}$ (Table 3 ). Only a few false signals and no dust impacts were recorded. The DIM health checks performed at Abydos did not indicate any non-nominal operation of DIM.

\subsection{Particle properties}

From the detected signal amplitude, $U_{\mathrm{m}}$, and the impact duration, $T_{\mathrm{c}}$, we can constrain the radius, $R$, and the impact speed, $v$, of the particle (Seidensticker et al. 2007; Flandes et al. 2013),

$T_{\mathrm{c}}=5.09\left(\frac{R^{5} \rho^{2}}{v E_{\mathrm{r}}^{2}}\right)^{1 / 5}$

and

$U_{\mathrm{m}}=\frac{3.03 d_{33} E_{\mathrm{r}}^{0.4} \rho^{0.6} R^{2} v^{1.2}}{C}$,

where $E_{\mathrm{r}}$ is the combined reduced modulus of the PZT sensor, $E_{\mathrm{PZT}}$, and the impinging particle $E_{\mathrm{p}}$ (see Flandes et al. 2013, for details).

From Eqs. (1) and (2) we define

$a=\left(\frac{5.09}{T_{\mathrm{c}}}\right)^{5}\left(\frac{\rho}{E_{\mathrm{r}}}\right)^{2}$

and

$b=\frac{3.03 d_{33} E_{\mathrm{r}}^{0.4} \rho^{0.6}}{U_{\mathrm{m}} C}$, 
Table 4. Average properties ${ }^{\dagger}$ of the PZTs and the particle.

\begin{tabular}{lcc}
\hline \hline Property & Symbol & Measured value \\
\hline Piezoelectric constant & $d_{33}$ & $239 \times 10^{-12} \mathrm{~m} \mathrm{~V}^{-1}$ \\
Capacitance & $C$ & $14.2 \mathrm{nF}$ \\
PZT's reduced Young's modulus & $E_{\mathrm{PZT}}$ & $74.5 \mathrm{GPa}$ \\
Particle's reduced Young's modulus & $E_{\mathrm{p}}$ & $>15 \mathrm{MPa}$ \\
Particle's bulk density & $\rho$ & $\gtrsim 250 \mathrm{~kg} \mathrm{~m}^{-3}$ \\
\hline
\end{tabular}

Notes. $\left.{ }^{(}\right) E_{\mathrm{p}}$ and $\rho$ were measured for aerogel (See Sect. 5.2 and Appendix B).

and solve for $R$ and $v$, getting

$v=\frac{a^{1 / 4}}{b^{5 / 8}}$

for the impact speed, and

$R=\left(\frac{1}{a^{6 / 5} b}\right)^{1 / 8}$

for the radius of the particle.

The piezoelectric constant, $d_{33}$; the capacitance of the PZT, $C$; and the reduced Young's modulus, $E_{\mathrm{r}}$, are known (see Flandes et al. 2013, 2014). These constants depend either on the properties of the PZTs, the properties of the impacting particles, or both. The parameter $\rho$ is the bulk density of the particle. A summary of these constants is given in Table 4 .

The $U_{\mathrm{m}}$ and $T_{\mathrm{c}}$ values are measured by the DIM electronics. However, as mentioned in Sect. 3, only the amplified output voltage $\left(U_{\text {out }}\right)$ is stored and, therefore, $U_{\mathrm{m}}$ needs to be derived from the known amplifier transfer function of the DIM electronics, which is given by Eq. (A.2) in Appendix A.

From our calibration experiments, it was found that the $U_{\mathrm{m}}$ and $T_{\mathrm{c}}$ values recorded by the DIM electronics are sensitive to the shape of the signal produced by the particle impacts and to the margin set for the measurements. For the particle detected by DIM during the descent, $U_{\text {out }}=2070 \mathrm{mV}$ and thus, from Eq. (A.2), $U_{\mathrm{m}}=2.45 \mathrm{mV}$. Given the small input voltage and very long impact duration $\left(T_{\mathrm{c}}=61 \mu \mathrm{s}\right)$, we assume that the impacting particle is quite likely a porous conglomerate with reduced Young's modulus larger than $10 \mathrm{MPa}$. This assumption is supported by calibration experiments performed with aerogel particles that have a bulk density of $\rho \approx 250 \mathrm{~kg} \mathrm{~m}^{-3}$ and Young's modulus $E_{\mathrm{p}}=15 \mathrm{MPa}$. The signal amplitudes and impact durations measured with aerogel are consistent with the values recorded by the DIM electronics at the comet (see Appendix B for details). We therefore use the results from our experiments with aerogel particles to estimate the properties of the particle detected by DIM.

Figure 6 shows the relationship between $v, R$, and $E_{\mathrm{p}}$, given the detected values $U_{\mathrm{m}}=2.45 \mathrm{mV}$ and $T_{\mathrm{c}}=61 \mu \mathrm{s}$ based on Eqs. (1) to (6). Estimations of the particle radius and speed are very sensitive to the values of $E_{\mathrm{p}}$. If we simply assume that the detected particle have properties equal to those of the aerogel mentioned above, we can conclude that its radius and its impact speed are about $1 \mathrm{~mm}$ and $1.95 \mathrm{~m} \mathrm{~s}^{-1}$ (the square in Fig. 6 highlights this case).

Nevertheless, in Flandes et al. (2013) we thoroughly discussed how the theoretical values deviate from the experimental data. We observed that, on average, the signal amplitudes $U_{\mathrm{m}}$ from the impacts could be underestimated by up to $30 \%$, while

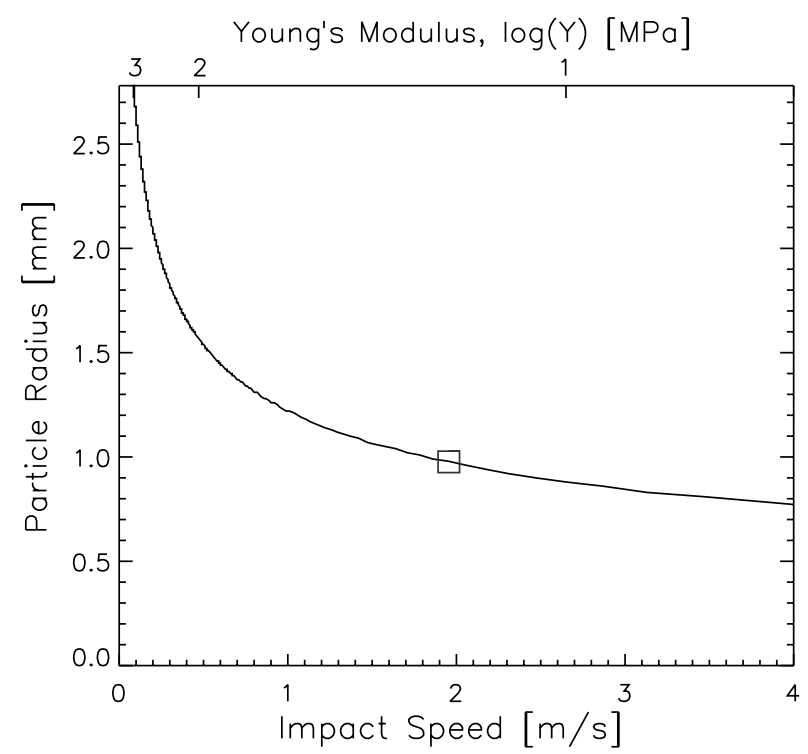

Fig. 6. Relationship between the impact speed $v$, radius $R$, and the Young's modulus $E_{\mathrm{p}}$ of the particles. The curve was derived from Eqs. (1) to (6), given the detected values $U_{\mathrm{m}}=2.45 \mathrm{mV}$ and $T_{\mathrm{c}}=61 \mu \mathrm{s}$. The square highlights the case where $E_{\mathrm{p}}=15 \mathrm{MPa}$ (aerogel), which yields $R=0.98 \mathrm{~mm}$ and $v=1.95 \mathrm{~m} \mathrm{~s}^{-1}$. The Young's modulus on a logarithmic scale is shown at the top. See text for details.

the impact durations $T_{\mathrm{c}}$ could be overestimated by up to $50 \%$ (this can be seen in Table 5, see also Appendix B), which means that the real $U_{\mathrm{m}}$ values could be larger and the real $T_{\mathrm{c}}$ values could be shorter than the recorded ones. Furthermore, our experiments as well as our theoretical calculations show that $T_{\mathrm{c}}$ is correlated with the Young's modulus of the material. This means that for a given impact speed the more elastic the material, the shorter the impact durations produced and vice versa. A similar effect applies to the voltage amplitude: for a given impact speed the more elastic the material, the more intense the voltage amplitude and vice versa. Thus, we conclude that for our detected particle the true values should be $U_{\mathrm{m}}>2.45 \mathrm{mV}$ and $T_{\mathrm{c}}<61 \mu \mathrm{s}$, and thus, $E_{\mathrm{p}}>15 \mathrm{MPa}$. Therefore, the derived radius of the particle should be a lower limit, $R>1 \mathrm{~mm}$, and the derived speed should be an upper limit, $v<1.95 \mathrm{~m} \mathrm{~s}^{-1}$, according to Fig. 6 . Furthermore, the Young's modulus of the nucleus surface may be as large as $500 \mathrm{MPa}$ (Gibson \& Ashby 1982), which implies an upper limit for the estimated particle radius of $2.3 \mathrm{~mm}$ and thus, a lower limit for the speed of $0.1 \mathrm{~m} \mathrm{~s}^{-1}$. The comparison of the evaluated speed range with speeds measured at 67P for compact particles (Della Corte et al. 2015) and for fluffy particles (Fulle et al. 2015) is in agreement with a porous nature of the particle.

Based on our analysis of the $\boldsymbol{U}_{\mathrm{m}}$ and $\boldsymbol{T}_{\mathrm{c}}$ values recorded by DIM during Philae's descent and our aerogel experiments (Appendix B) we conclude that the detected particle was very likely porous, with a porosity of about $40 \%$.

\subsection{Detection threshold and sensitivity range}

In order to estimate the sensitivity range of DIM, we assume a voltage range $0.2 \mathrm{mV}<U_{\mathrm{m}}<15 \mathrm{mV}$. This is shown in Fig. 7 where each black solid curve represents the particle's radius versus impact speed dependence for a constant signal amplitude $U_{\mathrm{m}}$. The lowest possible voltage that can be recorded is determined by the margin (see Sect. 3.4) that is determined by 
A\&A 583, A15 (2015)

Table 5. Measured voltage amplitude $U_{\mathrm{m}}$ and impact duration $T_{\mathrm{c}}$ for impacts of aerogel particles.

\begin{tabular}{ccccccc}
\hline \hline No. & $D[\mathrm{~mm}]$ & $U_{\mathrm{m}}[\mathrm{mV}]$ & $T_{\mathrm{c}}[\mu \mathrm{s}]$ & $D_{\mathrm{t}}[\mathrm{mm}]$ & $v_{\mathrm{t}}\left[\mathrm{m} \mathrm{s}^{-1}\right]$ & Notes \\
$(1)$ & $(2)$ & $(3)$ & $(4)$ & $(5)$ & $(6)$ & $(7)$ \\
\hline C1 & $5-7$ & 1.41 & 64.45 & 5.03 & 1.16 & Irregular, Fig. B.1C \\
C2 & & 6.06 & 58.79 & 5.70 & 3.23 & \\
\hline B1 & 5 & 2.18 & 77.40 & 5.96 & 1.21 & Irregular/spherical, Fig. B.1B \\
B2 & & 3.17 & 76.01 & 6.17 & 1.56 & \\
\hline A1 & 4 & 3.40 & 68.54 & 5.84 & 1.86 & Semi-spherical, Fig. B.1A \\
A2 & & 3.67 & 87.78 & 6.88 & 1.43 & \\
A3 & & 2.11 & 92.74 & 6.65 & 0.95 & \\
A4 & & 3.74 & 74.48 & 6.22 & 1.78 & \\
\hline
\end{tabular}

Notes. $D(\mathrm{Col} .2)$ is the diameter of the particle as shown in Fig. B.1. $D_{\mathrm{t}}(\mathrm{Col} .5)$ and $v_{\mathrm{t}}(\mathrm{Col} .6)$ are the diameter and speed derived from Eqs. (5) and (6) based on the measured amplitude $U_{\mathrm{m}}(\mathrm{Col} .3)$ and impact duration $T_{\mathrm{c}}(\mathrm{Col} .4)$. We assumed a density $\rho=250 \mathrm{~kg} \mathrm{~m}^{-3}$ and Young's modulus $E_{\mathrm{p}}=15 \mathrm{MPa}$. The measurements were obtained with an impact speed of about $0.94 \mathrm{~m} \mathrm{~s}^{-1}$ on the Z-side (3rd PZT) of DIM.

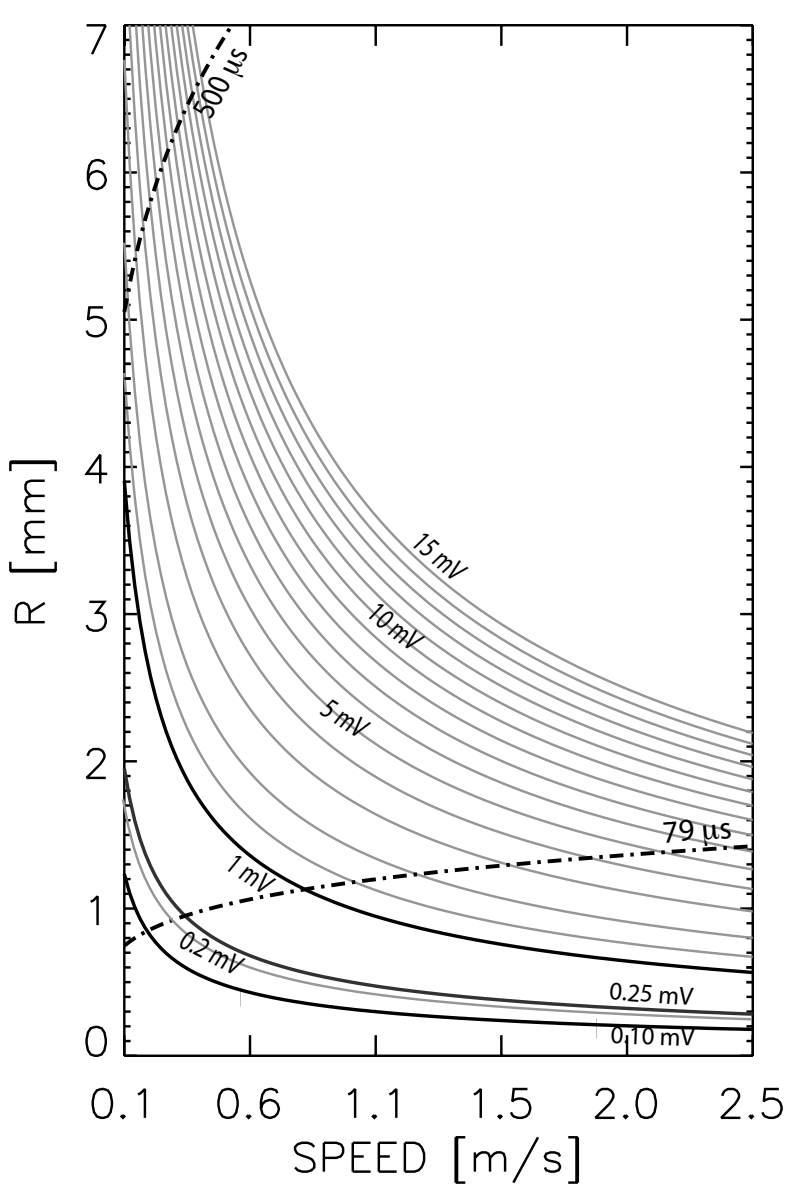

Fig. 7. Estimated detection range of DIM for porous ice particles. The curves are based on the mechanical properties of aerogel (bulk density of $250 \mathrm{~kg} \mathrm{~m}^{-3}$, average Young's modulus of $15 \mathrm{MPa}$, and Poisson ratio of 0.2). Measurement boundaries are specified as dashed lines (see text for details).

the instrument setup before the measurement. The margin values allowed by the flight software are $0.1(30 \mathrm{~dB}), 0.25(40 \mathrm{~dB})$, and $1.0 \mathrm{mV}(50 \mathrm{~dB})$, respectively, and are represented by continuous thick solid lines in Fig. 7. The corresponding impact durations that impacting porous particles could produce range from several tens to hundreds of microseconds. Furthermore, the DIM onboard electronics can only register impact durations up to a maximum value that is determined by the DIM operational mode (see Sect. 3.2 and Appendix A for details): the BC mode registers impact duration values up to $79 \mu$ s and the BCT2 mode up to $500 \mu \mathrm{s}$. These limits for the impact duration are represented by dashed lines in Fig. 7.

\section{Discussion}

The question arises of why DIM did not detect any dust impact at its final landing site Abydos. Two possible explanations are obvious. The first is shielding by ambient cliffs close to Philae. Reconstruction of Philae's surroundings from the images taken by the CIVA cameras (Bibring et al. 2015) indicates that Philae ended up in some type of cavity. This is also in agreement with very low ambient temperatures ranging from $90 \mathrm{~K}$ to $130 \mathrm{~K}$ between night and day (Spohn et al. 2015). Furthermore, Philae is likely tilted by about $90^{\circ}$ with respect to the local gravity vector. Reconstruction of the lander's orientation indicates that the $+Y$ sensor of DIM may be oriented towards open space while the $+X$ and the $+Z$ sensors are likely strongly shielded by cliffs that may be only a few meters away. The second explanation is the absence of cometary activity close to the landing site. The gas spectrometers on board Philae detected only a very low gas density (Goesmann et al. 2015; Morse et al. 2015), indicating that the landing site and its immediate vicinity were not active when DIM was taking measurements. Furthermore, owing to Philae's operational constraints at Abydos, most of the DIM measurements were performed at night when the comet was likely not active (Table 3 ).

The Rosetta Lander Imaging System (ROLIS; Mottola et al. 2007) detected one single dust particle in the vicinity of Philae at Abydos (Schröder et al. 2015). The ROLIS field of view is oriented towards the bottom of Philae ( $-Z$ direction). The particle is seen in front of one of the cliff walls, implying that it must have been in the cavity close to Philae. This particle could have been swept up from the cometary surface when Philae came to rest at Abydos. However, the size of the particle cannot easily be determined, and no other particles were detected in the cavity. Additional particles are visible in ROLIS and CIVA images, however, very likely at much larger distances from Philae.

Many particles can also be seen in images taken by the cameras on board Rosetta. These observations allowed the detection of particles likely on bound orbits around the comet nucleus and also fast and outflowing particles that had diameters of up to $17 \mathrm{~mm}$ were detected (Rotundi et al. 2015). Dynamical simulations showed that the orbits of millimeter- to centimeter-sized particles are relatively unstable while objects of a few decimeters and larger in diameter may stay in orbit about the cometary 
nucleus for years, i.e., a full orbital revolution of the comet around the Sun (Fulle 1997).

The long impact duration measured by DIM during the single particle detection cannot be reproduced by impacts of compact particles in laboratory experiments. However, we were able to obtain a very long impact duration in experiments with aerogel particles that had a density of $250 \mathrm{~kg} \mathrm{~m}^{-3}$ (see Appendix B), which indicates that the detected particle was likely a porous conglomerate.

The Cometary Secondary Ion Mass Analyzer (COSIMA) on board Rosetta also collected many porous particles in the size range up to a few hundred micrometers (Schulz et al. 2015). Most of these particles were collected at a distance between $10 \mathrm{~km}$ and $30 \mathrm{~km}$ from the cometary nucleus surface. The particles were very fragile so that many of them disintegrated during the collection process. The composition of these particles is not known yet, but they were not likely water ice particles.

The motion of particles under the influence of a very dilute gas has been studied by Tal (2014) using a Monte Carlo code. This code is similar to those described in Davidsson \& Skorov (2004) and Davidsson et al. (2010). Tal (2014) investigated two general scenarios. The first was an ice patch (spot) at some particular temperature, and the second was a jet. In the first case the gas flow was uncollimated, while in the second case the particle motion was calculated for different degrees of collimation of the gas flow. Tal found that for a spot at $155 \mathrm{~K}$, compact ice particles as large as $70 \mu \mathrm{m}$ could be lifted from the surface. The gas drag force on a particle is proportional to its cross section, so for a spherical particle of radius $a$ the drag force can be written as

$F_{\text {drag }}=\alpha a^{2}$,

where $\alpha$ is some constant. The gravitational force on the particle is proportional to its mass. For a spherical particle this means that

$F_{\text {grav }}=\beta \rho a^{3}$,

where $\beta$ is another proportionality constant and $\rho$ is the density of the particle material. The maximum radius of a liftable particle will be that for which the gravitational force on the particle exactly equals the drag force. In this case

$a_{\max }=\frac{\alpha}{\beta \rho}$

and the maximum radius of a liftable particle will be inversely proportional to the particle density.

Tal (2014) assumed particles with a density of $1000 \mathrm{~kg} \mathrm{~m}^{-3}$, corresponding to water ice, but if the material is porous, these results must be adjusted. The porosity, $p$, is defined as the fraction of the volume that is void of mass. Thus, if a compact body of mass $m$ occupies a volume $V$ so that

$\rho=\frac{m}{V}$,

then a body with mass $m$ and porosity $p$ will occupy a volume

$$
V=\frac{m}{(1-p) \rho}=\frac{m}{\rho^{*}},
$$

where $\rho^{*}=(1-p) \rho$ is the effective density of the porous material. This is the density that must be used in Eq. (7) so that the maximum radius of a liftable particle will be proportional to $((1-p) \rho)^{-1}$. These calculations assume that the trajectories of the gas molecules make random angles with the normal vector to the surface. However, if the gas is released as a collimated jet, the same gas production rate will provide a more efficient momentum transfer to the particle and somewhat larger particles will be lifted.

The Visible and Infrared Thermal Imaging Spectrometer (VIRTIS) on board Rosetta measured daytime surface temperatures between 180 and $230 \mathrm{~K}$ (Capaccioni et al. 2015). At these temperatures millimeter-sized compact particles can easily be lifted from the surface. For temperatures as low as $170 \mathrm{~K}$, Tal (2014) found that sublimation from a spot could lift compact particles of $5.4 \mathrm{~mm}$ radius off the surface. Porous (fluffy) particles could be proportionately larger. In view of this, it is entirely consistent that the particle seen by the DIM instrument was lifted off the comet's surface by sublimating water ice. While it is customary to use a total gas production rate instead of a temperature, this can be misleading if what is measured is the average value over a large area. In such a case local patches of activity can contribute much more gas (and drag) than would be expected from the average value, so that locally much larger particles can be lifted than would be expected from the average gas production rate.

The lifetime of a particle near the comet depends on its composition and albedo. Calculations of the lifetime of ice particles have been done by Beer et al. (2006). They find that pure ice particles larger than a few micrometers will survive for millions of years at around $3 \mathrm{AU}$. However, adding even a small amount of darker material sharply increases the heating rate so that micrometer-sized particles are only expected to survive for hours. In contrast, millimeter-sized particles of dirty ice could survive for many months. The results of Beer et al. (2006) are for compact ice particles. The rate of decrease in the radius $a$ of the particle is given by

$\frac{\mathrm{d} a}{\mathrm{~d} t}=\frac{P_{\mathrm{vap}}(T)}{\rho} \sqrt{\frac{m}{2 \pi k T}}$,

where $P_{\text {vap }}$ is the vapor pressure, $\rho$ is the density of the particle material, $m$ is the mass of a molecule of particle material, $k$ is Boltzmann's constant, and $T$ is the temperature of the particle. If the particle is porous, the mass density $\rho$ must again be replaced by $(1-p) \rho$ and the lifetime of the particle will be shortened proportionately. On the other hand, the lifetime of the particle will be greatly increased if it is composed of less volatile material such as organics or silicates.

Oblique impacts up to angles $\phi=50^{\circ}$ were examined in the course of the DIM calibration experiments reported by Flandes et al. $(2013,2014)$. The impact duration $T_{\mathrm{c}}$ increased by $5 \%$, while the amplitude decreased by $20 \%$, both following a cosine law. This entails that the parameter range for $R$ expands by $10 \%$ towards lower values if analyzed as perpendicular impact. There are additional effects when the impact angles become so large that sliding friction and rolling of the particle sets in $(\mathrm{Wu}$ et al. 2003). These effects further decrease the perpendicular impact force and increase the contact time. With only one detected event, it is not possible to take these effects into account.

\section{Conclusions}

Measurements with the Dust Impact Monitor (DIM) on board Philae were obtained before the separation from Rosetta, during Philae's descent to the nucleus surface, and at Philae's final landing site Abydos. Our results can be summarized as follows:

(1) DIM detected no dust before the separation of Philae from Rosetta during a measurement period of about $4.7 \mathrm{~h}$. This is 
most likely due to the unfavorable detection geometry of the DIM sensor and obscuration by the Rosetta spacecraft during this mission phase, which prevented the detection of particles ejected radially from the nucleus.

(2) One single dust impact was detected at an altitude of about $2.4 \mathrm{~km}$ during Philae's descent to its nominal landing site Agilkia. This was very likely a porous particle with radius $R \approx 1 \mathrm{~mm}$ that hit the sensor with an impact speed $v \approx$ $2 \mathrm{~m} \mathrm{~s}^{-1}$. The particle could have been lifted off the comet's surface by sublimating water ice.

(3) At Philae's final landing site Abydos, DIM detected no dust particle during a total measurement period of $5 \mathrm{~h}$. This may be due to the strong obscuration of DIM by the ambient cliffs, to the very low cometary activity at Abydos because most of the measurements were taken at night, or to other effects.

The particle detection at $2.4 \mathrm{~km}$ altitude is the closest dust detection ever performed by a dedicated dust instrument at a cometary nucleus. In June 2015 contact with Philae was established again, which may provide the possibility for additional DIM measurements at Abydos. The detection of more dust particles would allow us to better constrain the small scale properties of the cometary nucleus material.

Acknowledgements. SESAME is an experiment on the Rosetta lander Philae. It consists of three instruments CASSE, DIM and PP, which were provided by a consortium comprising DLR, MPS, FMI, MTA EK, Fraunhofer IZFP, Univ. Cologne, LATMOS and ESTEC. The contribution from MTA EK to the SESAME-DIM experiment was co-funded through the PRODEX contract No. 90010 and by the Government of Hungary through European Space Agency contracts No 98001, 98072, 4000106879/12/NL/KML and 4000107211/12/NL/KML under the plan for European Cooperating States (PECS). This research was supported by the German Bundesministerium für Bildung und Forschung through Deutsches Zentrum für Luft- und Raumfahrt e.V. (DLR, grant 50 QP 1302). Support by MPI für Sonnensystemforschung is gratefully acknowledged. A. Flandes was also supported by DGAPA-PAPIIT IA100114. We thank Lorenz Ratke and Benjamin Ignatzi (DLR Institut für Werkstoffforschung Köln) for providing us with aerogel samples for impact calibration experiments. We are grateful to Cynthia Volkert and Cornelia Mewes (Institute for Materials Science, University of Göttingen) for supporting us with measurements of the Young's modulus of the aerogel particles. We thank the Rosetta project at ESA and the Philae project at DLR and CNES for effective and successful mission operations, and the GIADA team from providing us with predicted dust fluxes for DIM. We are grateful to an anonymous referee for helpful suggestions concerning the presentation of our results.

\section{Appendix A: Impact parameters}

\section{Impact duration}

The conversion between the number of counts $n$ of the $20 \mathrm{MHz}$ clock and the impact duration $\boldsymbol{T}_{\mathrm{c}}$ in an internally defined logarithmic scale is given by

$$
\boldsymbol{T}_{\mathrm{c}}=20 \cdot \log _{10}(2 \cdot n)=20 \cdot \log _{10}\left(\frac{40 \cdot T_{\mathrm{c}}}{10^{-6} \mathrm{~s}}\right) .
$$

The results of Eq. (A.1) are rounded to the nearest integer value. Impacts with $\boldsymbol{T}_{\mathrm{c}} \geq 70$ are stored as if they were impacts with $\boldsymbol{T}_{\mathrm{c}}=70$, thus impact durations larger than $79 \mu$ s cannot be distinguished in the $\mathrm{BC}$ mode.

Telemetry of the BCT2 mode also includes the counter value $n$. Therefore, this mode delivers impact durations of all accepted impacts with a time resolution of $0.05 \mu \mathrm{s}$.

The measuring range is limited by the clock frequency (20 MHz corresponding to a resolution of $50 \mathrm{~ns}$; with $6 \mathrm{~dB}$ bandwidth) and depends on the operation mode. Thus, the
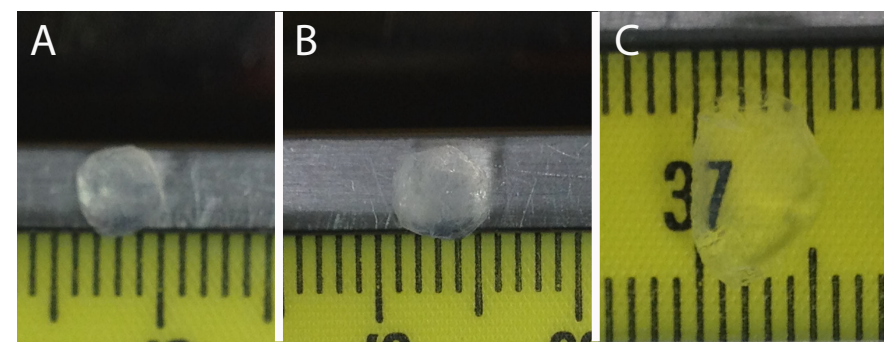

Fig. B.1. Aerogel particles (bulk density, $\rho \approx 250 \mathrm{~kg} \mathrm{~m}^{-3}$ ) used in the impact experiments reported in Table 5.

following instrument limits have been specified: $T_{\mathrm{c}, \min }=100 \mathrm{~ns}$, $T_{\mathrm{c}, \max , \mathrm{BC}}=79 \mu \mathrm{s}$ for $\mathrm{BC}$ mode and $T_{\mathrm{c}, \max , \mathrm{BCT} 2}=500 \mu \mathrm{s}$ for BCT2 mode.

\section{Peak voltage}

The conversion between the signal generated by the piezoelectric sensors and the amplified signal is given by the amplifier transfer function of the DIM flight model (Péter 2002),

$U_{\text {out }}[V]=3.61+0.59 \log _{10}\left(\frac{U_{\mathrm{m}}}{U_{\mathrm{r}, 1}}\right)$,

where $U_{\mathrm{r}, 1}=1 \mathrm{~V}$ is a reference voltage. The logarithmic amplifier was designed such that the maximum output voltage is $U_{\text {out,max }}=3 \mathrm{~V}$. Equation (A.2) was determined by calibration procedures.

For storage of the DIM data a decibel scale relative to $U_{\mathrm{r}, 2}=$ $5.355 \mu \mathrm{V}$ is used so that a $3 \mathrm{~V}$ output signal of the logarithmic amplifier corresponds to $85.4 \mathrm{~dB}$ in the input signal relative to the reference voltage $U_{\mathrm{r}, 2}$, which is arbitrary and is given by the development history of the DIM instrument. Hence,

$\boldsymbol{U}_{\text {out }}[d B]=20 \cdot \log _{10}\left(\frac{U_{\mathrm{m}}}{U_{\mathrm{r}, 2}}\right)=20 \cdot \log _{10}\left(\frac{U_{\mathrm{m}}}{5.355 \times 10^{-6} \mathrm{~V}}\right)$.

After some simple mathematics, Eqs. (A.2) and (A.3) can be transformed into

$\boldsymbol{U}_{\text {out }}[d B]=20 \cdot \log _{10}\left(\frac{U_{\mathrm{m}}}{U_{\mathrm{r}, 2}}\right)=\frac{U_{\text {out }}-0.5}{0.03}$.

\section{Appendix B: Laboratory experiments with aerogel}

In addition to the calibration experiments reported by Flandes et al. (2013, 2014), we performed impact experiments with a flight spare sensor of DIM at the Max-Planck-Institut für Sonnensystemforschung. We used high-density aerogel (bulk density $\rho \approx 250 \mathrm{~kg} \mathrm{~m}^{-3}$ and Young's modulus $E_{\mathrm{p}}=15 \mathrm{MPa}$ ) which - to a first approximation - is a material whose density and Young's modulus are close to porous ice.

The three aerogel particles shown in Fig. B.1 were released from a height of $4.5 \mathrm{~cm}$ (which corresponds to an impact speed of approximately $0.94 \mathrm{~m} \mathrm{~s}^{-1}$ ) onto the center of the third PZT of the Z-side of a DIM flight spare sensor (normal impacts). These particles produced low impact amplitudes of a few millivolts as well as long contact durations of many tens of microseconds. These values are consistent with those recorded by the DIM onboard electronics during our particle impact. The values obtained during our impact experiments are shown in Table 5 and the signals generated by the almost spherical particle (Fig. B.1A) from the oscilloscope data are shown in Fig. B.2. In Flandes et al. $(2013,2014)$ we discuss in detail how the theoretical values deviate from the experimental data. 


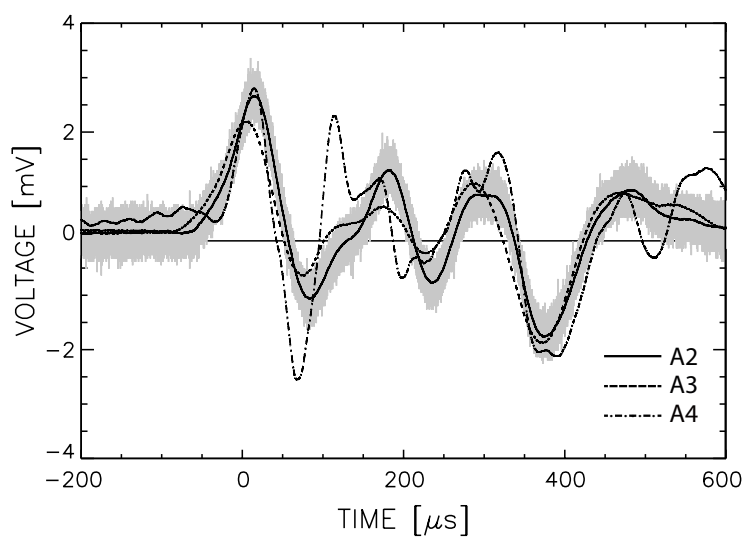

Fig. B.2. Impact signals generated by the semi-spherical aerogel particle A (Fig. B.1A and Table 5, experiments A2 to A4). All curves except the gray one are smoothed in order to remove noise. The solid black curve (A2) and the gray curves are the same. The gray curve illustrates the noise of each signal.

\section{Appendix C: Error estimation}

Columns (5) and (6) in Table 5 show the theoretically estimated particle diameter, $D_{\mathrm{t}}$, and impact speed, $v_{\mathrm{t}}$, calculated with Eqs. (5) and (6) and with the measured signal amplitude $U_{\mathrm{m}}$ and impact duration $T_{\mathrm{c}}$ (Cols. 3 and 4 in Table 5). The measured values do not represent a rigorous statistical analysis, but they show that the detected particle could be as porous as aerogel, having a density and Young's modulus of the same order of magnitude as aerogel. The average estimated uncertainties of these values with respect to the measured signal amplitudes and impact durations (Cols. 3 and 4) are about $40 \%$ for the diameter and $50 \%$ for the speed. Furthermore, our analysis assumes that the impacting particles are spherical (cf. Sect. 5.2), which is certainly only a rough approximation. The shape plays a significant role as well, as can be seen in Table 5 .

\section{References}

Adliene, D., Pranevicius, L., \& Ragauskas, A. 1985, Nucl. Instrum. Methods Phys. Res., 6, 435

Agarwal, J., Böhnhardt, H., \& Grün, E. 2007, in Dust in Planetary Systems (Workshop, September 26-30 2005, Kauai, Hawaii), eds. H. Krüger, \& A. L. Graps, ESA SP, 643, 51

A'Hearn, M. F., Belton, M. J. S., Delamere, W. A., et al. 2011, Science, 332, 1396

Auster, H. U., Apathy, I., Berghofer, G., et al. 2015, Science, 349, aaa5102 Beer, E. H., Podolak, M., \& Prialnik, D. 2006, Icarus, 180, 473

Bibring, J.-P., Rosenbauer, H., Böhnhardt, H., et al. 2007, Space Sci. Rev., 128, 205

Bibring, J.-P., Langevin, Y., Carter, J., et al. 2015, Science, 349, aab0671 Biele, J., Ulamec, S., Maibaum, M., et al. 2015, Science, 349, aaa9816
Capaccioni, F., Coradini, A., Filacchione, G., et al. 2015, Science, 347, aaa0628 Davidsson, B. J. R., \& Skorov, Y. V. 2004, Icarus, 168, 163

Davidsson, B. J. R., Gulkis, S., Alexander, C., et al. 2010, Icarus, 210, 455

Della Corte, V., Rotundi, A., Fulle, M., et al. 2015, A\&A, 583, A13

Economou, T. E., Green, S. F., Brownlee, D. E., \& Clark, B. C. 2013, Icarus, 222,526

Fischer, H.-H. 2012, SESAME Flight Software FM-3 - Telecommands and Telemetry Formats, ROSETTA Tech. Rep. RO-LSE-UG-3404, version 5.5a

Fischer, H.-H. 2014, Considerations on DIM Detection Efficiency (Single Impacts) and the Current Situation of DIM Calibration, SESAME document, unpublished

Flandes, A., Krüger, H., Loose, A., et al. 2013, Planet. Space Sci., 84, 122

Flandes, A., Krüger, H., Loose, A., Albin, T., \& Arnold, W. 2014, Planet. Space Sci., 99, 128

Fulle, M. 1997, A\&A, 325, 1237

Fulle, M., Della Corte, V., Rotundi, A., et al. 2015, ApJ, 802, L12

Gibson, L., \& Ashby, M. 1982, Proc. Roy. Soc. London Series A - Mathematical Physical and Engineering Sciences, 382, 43

Glassmeier, K.-H., Böhnhardt, H., Koschny, D., Kührt, E., \& Richter, I. 2007, Space Sci. Rev., 128, 1

Goesmann, F., Rosenbauer, H., Bredehöft, J.-H., et al. 2015, Science, 349, aab0689

Hertz, H. 1882, Journal über die reine und angewandte Mathematik, 92, 156

Hirn, A., Albin, T., Fischer, H. H., et al. 2015, DIM SDL and FSS Detailed Status Report, ROSETTA Tech. Rep. RO-LSE-AN-3140, Issue v1.00

Holbert, K., Sankaranarayanan, S., \& McCready, S. 2005, IEEE Trans. Nucl. Sci., 52, 2583

Jenniskens, P. 2006, Meteor Showers and their Parent Comets (Cambridge University Press)

Johnson, K. L. 1985, in Contact Mechanics (Cambridge University Press), 351

Kofman, W., Herique, A., Barbin, Y., et al. 2015, Science, 349, aab0639

Krüger, H., Loose, A., Flandes, A., et al. 2012, DIM Calibration Measurements Köln 11 to 13 July 2011, SESAME Tech. Rep., version of 26 Sept.

Lamy, P. L., Toth, I., Davidsson, B. J. R., et al. 2007, Space Sci. Rev., 128, 23

McDonnell, J. A. M., Lamy, P. L., \& Pankiewicz, G. S. 1991, in Comets in the Post-Halley Era, eds. R. L. Newburn, M. Neugebauer, \& J. Rahe (Kluwer), 1043

Miyachi, T., Nakamura, Y., Kuraza, G., et al. 2006, Nucl. Instrum. Meth. Phys. Res., A 568, 760

Miyachi, T., Fujii, M., Hasebe, N., et al. 2010, J. Appl. Phys., 107, 104902

Morse, A., Mousis, O., Sheridan, S., et al., A. 2015, A\&A, 583, A42

Mottola, S., Arnold, G., Grothues, H.-G., et al. 2007, Space Sci. Rev., 128, 241

Mottola, S., Lowry, S., Snodgrass, C., et al. 2014, A\&A, 569, L2

Péter, A. 2002, Performance Report of DIM, ROSETTA Tech. Rep. RO-LSETP-3445, Issue 1

Péter, A., \& Lucás, V. 2001, DIM Software Description, SESAME document RO-LSE-SP-3440, version 4

Preusker, F., Scholten, F., Matz, K.-D., et al. 2015, A\&A, 583, A33

Rotundi, A., Sierks, H., Della Corte, V., et al. 2015, Science, 347, aaa3905

Schröder, S., Mottola, S., Arnold, G., et al. 2015, Geophys. Res. Abstracts, 17, eGU2015-10990, EGU General Assembly

Schulz, R., Hilchenbach, M., Langevin, Y., et al. 2015, Nature, 518, 216

Seidensticker, K. J., Möhlmann, D., Apathy, I., et al. 2007, Space Sci. Rev., 128, 301

Spohn, T., Knollenberg, J., Ball, A. J., et al. 2015, Science, 349, aab0464

Tal, V. 2014, Ph.D. Thesis, Tel-Aviv University, Israel

Thomas, N., Sierks, H., Barbieri, C., et al. 2015, Science, 347, aaa0440

Tozzi, G. P., Patriarchi, P., Böhnhardt, H., et al. 2011, A\&A, 531, A54

Tuzzolino, A. J., Economou, T. E., Clark, B. C., et al. 2004, Science, 304, 1776

Wu, C., Thornton, C., \& Li, L. 2003, Advanced Powder Technology, 14, 435, www. vsppub.com 